\title{
The influence of NMDA receptor $2 B$ subunit (GRIN2B) on cortical electrical oscillation
}

\author{
Tien-Wen Lee ${ }^{1,2}$, Younger W-Y Yu ${ }^{3}$, Chen-Jee Hong ${ }^{4,5}$, Shih-Jen Tsai ${ }^{4,5}$, Hung-Chi Wu ${ }^{6}$, Tai-Jui Chen ${ }^{7,8}$ \\ ${ }^{1}$ Department of Psychiatry, Chang Gung Memorial Hospital, Taoyuan County, Chinese Taipei; \\ ${ }^{2}$ College of Medicine, Chang Gung University, Taoyuan County, Chinese Taipei; \\ ${ }^{3}$ Yu's Psychiatric Clinic, Kaohsiung, Chinese Taipei; \\ ${ }^{4}$ Department of Psychiatry, Taipei Veterans General Hospital, Taipei, Chinese Taipei; \\ ${ }^{5}$ School of Medicine, National Yang-Ming University, Taipei, Chinese Taipei; \\ ${ }^{6}$ Kai-Suan Psychiatric Hospital, Kaohsiung, Chinese Taipei; \\ ${ }^{7}$ Department of Psychiatry, E-DA Hospital, Kaohsiung County, Chinese Taipei; \\ ${ }^{8}$ Department of Occupational Therapy, I-Shou University, Kaohsiung County, Chinese Taipei. \\ Email: tjchen71@kimo.com
}

Received 21 June 2011; revised 26 September 2011; accepted 9 October 2011.

\section{ABSTRACT}

The N-methyl D-aspartate receptor (NMDAR) is composed of several subunits. Among them, the N2B is of interest, given its dominance in early development and its significant impact on neuronal channel functioning and the formation or maintenance of cellular architecture. NMDAR-N2B, also named GRIN2B, has been implicated in broad neuro-psychiatric conditions. However, the genetic impact on cortical oscillation in the human brain is still unclear. This study examined the modulatory effects of a silent mutation C2644T polymorphism on the EEG oscillation. Blood samples were collected and resting state eyes-closed EEG signals were recorded in 256 young healthy females, stratified into three groups according to genotypes $\mathrm{C} / \mathrm{C}, \mathrm{C} / \mathrm{T}$ and $\mathrm{T} / \mathrm{T}$. The values of the mean power of 18 electrodes across delta, theta, alpha, beta and gamma frequencies were analyzed. Between-group statistics were determined by ANOVA and independent t-test; and a global trend of regional power was quantified by non-parametric analyses. No significant between-group differences were noticed with the statistical threshold after Bonferroni correction. At less conservative threshold of $P<0.01, C / T$ group had higher regional power at sparse electrode-frequency pairs in posterior brain regions. However, a consistent global trend was noticed wherein the $\mathrm{C} / \mathrm{T}$ group possessed higher EEG powers, regardless of spectral bands. Nonparametric analyses confirmed this observation. Our results implied that the heterozygous group of GRIN2B C2744T was associated with higher neural synchronization during relaxation, which may be relevant to the impact of GRIN2B in early development and the
inverted-U-shaped response in the NMDA system.

Keywords: Electroencephalography (EEG); Power Spectrum; NMDA; Polymorphism

\section{INTRODUCTION}

The NMDA (N-methyl D-aspartate) receptor (NMDAR) is a specific type of ligand-gated ionotropic glutamate receptor named after the selective agonist. NMDA system plays significant roles in synaptic plasticity, learning and memory, and in the pathological processes in the brain. Functional NMDA receptors are composed of several subunits, namely NR1, NR2A-D and NR3A-B, with their various heteromeric assemblies determining the physiological properties of NMDAR. The activation of NMDAR results in the opening of an ion channel that is non-selective to cations, and which requires the presence of an agonist (e.g. glutamate), a co-transmitter (glycine or dserine) and depolarization, rendering the property of coincidence detector. The excitatory postsynaptic potential produced by the activation of NMDAR increases the concentration of $\mathrm{Ca}^{2+}$ in the cell, which in turn functions as a second messenger in various signaling pathways. NMDAR is widely distributed in the central nervous system, and the antagonist of NMDAR is well-known to induce psychosis, which has contributed to the development of the NMDAR hypofunction hypothesis of schizophrenia [1]. Although still debated, NMDAR has been implicated in broad neuro-psychiatric conditions, such as Alzheimer's disease, Huntington's disease, neuronal damage after stroke, epileptogenesis in cortical dysplasia, anorexia nervosa, obsessive-compulsive disorder and alcohol-related risk, behaviors and neural changes [2-16]. 
Unlike the NR1 subunit common to all NMDAR, NR2 subunits are expressed differentially across various cell types and hence affect the electrophysiological kinetics of NMDARs. In normal development, there is a phenomenon called NR2B-NR2A switch of NMDAR. NR2B is predominant in the early postnatal brain; however, during development, the subunit composition of synaptic NMDARs changes, switching from predominance of NR2B-containing receptors to NR2A-containing receptors. This process is critical to survival, given that animal studies demonstrated perinatal lethality after a disruption of the gene for NR2B, whereas the disruption of the NR2A gene produced viable mice, although with impaired hippocampal plasticity [17-19]. In the rat model of focal ischemic stroke, activation of synaptic/extrasynaptic NR2A-containing and NR2B-containing NMDAR imposed opposite effects on neurons, with the former exerting a protective action that promoted neuronal survival and the latter enhancing excitotoxicity, which increased neuronal apoptosis [2]. The NR2B subunit is involved in the synapse development, macro-molecular organization, the actin cytoskeleton and plasticity [20]; however, its precise function is relatively hard to access because the knock-out manipulation would lead to lethality.

The NMDAR-NR2B (GRIN2B) gene, consisting of 13 exons, is located at $12 \mathrm{p} 12$, with a size of $419 \mathrm{~kb}$. It is expressed in the hippocampus, basal ganglia and cerebral cortex [21], and was implicated in the risk or susceptibility of schizophrenia, obsessive-compulsive disorder, Alzheimer's disease and alcohol consumption patterns [1,3,6$8,12]$. The behavioral profiles of pre-pulse inhibition were also affected by GRIN2B [22,23]. A polymorphism C2664T of GRIN2B at exon 13, rs1806201, results in a silent mutation (synonymous mutation) where the codon of ACC is replaced by ACT, both encoding the same amino acid Threonine. Although silent mutations do not alter protein function, they are not always evolutionarily neutral. It may be due to codon usage biases that there is selection for the use of particular codons due to different translational stability. Silent mutations may also affect splicing or transcriptional control. Association studies suggested that GRIN2B C2664T polymorphism may possess clinical significance, such as differentiating the anti-psychotic dosage in psychosis and the susceptibility to alcoholism $[8,12,24]$. Whether GRIN2B C2664T polymorphism modulate brain activity is still unclear. This study planned to investigate the effect of GRIN2B C2664T polymerphism on resting EEG, which has never been examined before.

Different genotypes GRIN2B C2664T may affect the quantity, not the quality, of NR2B. It is noteworthy that, as with the dopamine system, the dose response of NMDAR also follows a non-linear, inverted-U-shaped, pharmacological profile [25-27]. To delineate the genetic influence of GRIN2B C2664T polymorphisms on the cortico-electrical activities at the resting state, we stratified our participants into three groups: $\mathrm{C} / \mathrm{C}, \mathrm{C} / \mathrm{T}$ and $\mathrm{T} / \mathrm{T}$; in case the two-group approach based on the carriage of $\mathrm{C}$ or $\mathrm{T}$ allele may mask significant differences if the polymorphism exerts impact on the ascending and/or the descending limbs of the inverted-U-response curve. Resting EEG carries abundant information predictive of performance in several neuro-psychological tasks, and even the early stage of Alzheimer's disease or the treatment response of major depressive disorder [28-33]. Recent studies have suggested that polymorphisms of GRIN2B influence phenotypic behavior and pathological condition in a gender-dependent manner [34,35]. For this pilot study, we restricted our sample to the female gender and to a limited age range to simplify any gender or chronological interaction. Regional as well as global effects were examined. See method section for details.

\section{MATERIALS ANd METHODS}

\subsection{Subjects}

We recruited 256 right-handed healthy young females, aged 19 to 21 years. Licensed medical doctors and psychiatrists respectively examined their neurological/physical and psychiatric conditions. The exclusion criteria included major medical or neurological disorders, substance abuse or psychiatric disease. All participants had been medication-free for at least two weeks. This project was approved by the local ethical committee, and written informed consent was obtained from all subjects prior to participation in this study.

\subsection{EEG Recordings and Analyses}

We recorded 3-minute resting digital EEG with cupshaped passive electrodes in both the eyes-closed and awake state (Brain Atlas III computer, Biologic System Company, Chicago). The recording started after a 5-minute habituation to the experimental environment, following the standard of the international 10-20 system with earlinked reference, at a $128 \mathrm{~Hz}$ sampling rate, high pass filter $0.05 \mathrm{~Hz}$, low pass filter $70 \mathrm{~Hz}$, notch filter 60 $\mathrm{Hz}$ and impedance below $3 \mathrm{k} \Omega$ after skin preparation [36]. Vertical and horizontal eyeball movements were respecttively monitored from the electrodes placed above and below the right eye, and the electrodes placed at the left outer canthus. EEG artifacts were handled by semi-automated module provided by software EEGLAB (http://sccn.ucsd.edu/eeglab). The artifact segments from various sources, such as external artifact, movements, oculogenic potentials and myogenic potentials and so on, were detected and deleted via visual inspection by experienced EEG technician and then the signal quality was examined by channel statistics and QQ-plot. The EEG channels were re-checked and trimmed until passing 
Kolmogorov-Smirnov test $(\mathrm{P}<0.05)$, i.e. the EEG signals acting like normal distribution. The electrodes F7, F3, Fz, F4, F8, T3, C3, Cz, C4, T4, T5, P3, Pz, P4, T6, $\mathrm{O} 1, \mathrm{Oz}$ and $\mathrm{O} 2$ were included in the analyses. The frequency bands were defined as follows: theta 4 to $8 \mathrm{~Hz}$, alpha 8 to $12 \mathrm{~Hz}$, beta 12 to $24 \mathrm{~Hz}$, beta1 12 to $18 \mathrm{~Hz}$ and beta2 18 to $24 \mathrm{~Hz}$, gamma 25 to $60 \mathrm{~Hz}$, gamma1 25 to $35 \mathrm{~Hz}$ and gamma2 35 to $60 \mathrm{~Hz}$. Fast Fourier Transform (FFT) was used to derive the mean EEG power for each electrode at a specified frequency band for each artifact-free segment (unit: $\mu \mathrm{V}^{2}$ ). The mean power spectrum were further normalized and weighted by the lengths of artifact-free segments, and summed to generate the reported mean power spectrum.

\subsection{Genotyping of GRIN2B Polymorphism}

Genomic DNA was extracted from peripheral blood leukocytes and was amplified using polymerase chain reaction (PCR). The genotypes of GRIN2B C2664T were identified following reported methods [5,37]. In brief, we designed primers 5'-AGA CTA TTC GCT TCA TGC-3' and 5'-GTG TGT TGT TCA TGG CTG-3' to create 210bp PCR product with a PstI restriction site, which enables differentiating the $2664 \mathrm{~T}$ and $2664 \mathrm{C}$ polymerphisms.

\subsection{Statistical Analyses}

The participants were categorized into 3 groups according to the GRIN2B C2664T polymorphism, namely $\mathrm{C} / \mathrm{C}$, $\mathrm{C} / \mathrm{T}$ and $\mathrm{T} / \mathrm{T}$ groups. Analysis of variance (ANOVA) and independent t-test with assumed unequal variance were performed to elucidate the electrodes with values of mean power showing significant between-group differences. For each test set in this study, the criterion for significance was set at $P<0.05$, two-tailed. We assumed the independency of each frequency band and performed the Bonferroni correction based on $P=1-(1-0.05)^{1 / n}$, where $n$ equals the number of comparisons, with $n=18$ equivalent to the electrode number. For each comparison, we reported both the $P$ value $<0.01$ and the $P$ value adjusted for multiple comparisons, in case the Bonferroni correction might be too stringent since the cortical electrical activities are interactive rather than totally independent. The regional mean EEG power at frontal (F7, F3, Fz, F4, F8), temporal (T3, T4, T5, T6), centro-parietal $(\mathrm{P} 3, \mathrm{Pz}, \mathrm{P} 4)$ and occipital $(\mathrm{O} 1, \mathrm{Oz}, \mathrm{O} 2)$ regions were computed to compare the between-group differences ( $\mathrm{n}=4, P=0.0127$ after Bonferroni correction). To test whether there was a global trend difference in the mean power across regions and frequency bands between the three genotyped groups, we performed non-parametric analyses. Our null hypothesis assumed that the probability of a certain index (i.e., mean power) for a particular electrode at a specific frequency band that one group is greater than another group equals the probability that group two is greater than group one (i.e., the probability was 0.5 ). The probability of obtaining $\mathrm{j}$ or more "group one > group two" indices by chance can be calculated by:

$$
\mathrm{P}=\sum_{\mathrm{k}=\mathrm{j}}^{\mathrm{s}}\left(\begin{array}{l}
\mathrm{s} \\
\mathrm{k}
\end{array}\right) \times 0.5^{\mathrm{s}},
$$

where $\mathrm{s}$ is the total number of comparisons, with $\mathrm{s}=18$ $\times 9$ when taking all the electrode(18)-frequency(9) pairs into account).

\section{RESULTS}

The GRIN2B C2664T genotypes of the participants included $\mathrm{C} / \mathrm{C}(\mathrm{N}=61), \mathrm{C} / \mathrm{T}(\mathrm{N}=126)$ and $\mathrm{T} / \mathrm{T}(\mathrm{N}=69)$, distributed in Hardy-Weinberg equilibrium $(\chi 2=0.055$, $P=0.815)$. The subjects were divided into three groups according to their genotypes, so there were three between-group comparisons, $\mathrm{C} / \mathrm{C}$ vs. $\mathrm{C} / \mathrm{T}, \mathrm{C} / \mathrm{C}$ vs. $\mathrm{T} / \mathrm{T}$ and $\mathrm{C} / \mathrm{T}$ vs. $\mathrm{T} / \mathrm{T}$. The ANOVA analyses of mean power did not reveal significant between-group differences at all the electrode-frequency pairs (minimum of $P=0.0124$ ) after the Bonferroni correction $(P=0.0028)$. At a looser threshold with $P 0.01$, independent t-tests revealed that the $\mathrm{C} / \mathrm{T}$ group had a higher mean power at $\mathrm{Fz}$ gamm2 and $\mathrm{P} 4$ gamma/gamma1/gamma2 when compared with the $\mathrm{C} / \mathrm{C}$ group, and had a higher mean power at $\mathrm{T} 3$ beta/beta1/beta2, T4 gamma/gamma2, Pz gamma/gamma2, T6 gamma1, O1 gamma/gamma1, Oz gamma/gamma1 and $\mathrm{O} 2$ beta 2 when compared with the $\mathrm{T} / \mathrm{T}$ group. None of the power differences reached $P<0.01$ for $\mathrm{C} / \mathrm{C}$ and $\mathrm{T} / \mathrm{T}$ comparison.

We performed non-parametric analyses to examine the genetic effect of GRIN2B on the global trend of EEG power. Strikingly, we discovered that out of the 162 electrode-frequency pairs (18 electrode and 9 frequency bands), there were 161 comparisons that $\mathrm{C} / \mathrm{T}>\mathrm{C} / \mathrm{C}$ and 159 comparisons that $\mathrm{C} / \mathrm{T}>\mathrm{T} / \mathrm{T}$, with respective $\mathrm{P}$ value $2.771 \times \exp (-47)$ and $1.212 \times \exp (-43)$. The $\mathrm{C} / \mathrm{C}$ group had 79 electrode-frequency pairs showing a smaller mean power than the T/T group, with $P$ value 0.6527 . In summary, the heterozygous $\mathrm{C} / \mathrm{T}$ group had a global trend of higher cortico-electrical power than the $\mathrm{C}$ and $\mathrm{T}$ homozygous counterparts, which seemed more prominent in posterior brain regions. Interested readers may refer to the supplementary material of the detailed results (Table S1 to S3 for three between-group comparisons, at http://www.websdj.idv.tw/kiki/rEEG NMDA.pdf).

To ensure that our results were not caused by outliers, we made another analyses that for each genotypic group, each frequency band and each electrode site, we registered the participants with power value deviating the mean by greater than 3 standard deviations and then remove all of them from the non-parametric analyses. We have 196 subjects left, with $\mathrm{C} / \mathrm{C}=46, \mathrm{C} / \mathrm{T}=97, \mathrm{~T} / \mathrm{T}=53$. 
Among the 162 electrode-frequency pairs (18 electrode and 9 frequency bands), there were 151 comparisons that $\mathrm{C} / \mathrm{T}>\mathrm{C} / \mathrm{C}$ and 147 comparisons that $\mathrm{C} / \mathrm{T}>\mathrm{T} / \mathrm{T}$, with respective $\mathrm{P}$ value $6.581 \times \exp (-33)$ and $1.035 \times \exp (-28)$. The $\mathrm{C} / \mathrm{C}$ group had 108 electrode-frequency pairs showing a smaller mean power than the T/T group, with $\mathrm{P}$ value 0.1535 . See Figure $\mathbf{1}$ and $\mathbf{2}$ to appreciate the global trend in between-group comparisons.

The analyses of regional mean power demonstrated that $\mathrm{C} / \mathrm{T}$ group is greater than $\mathrm{C} / \mathrm{C}$ group and $\mathrm{T} / \mathrm{T}$ group at each frequency-region pair, consistent with the nonparametric analyses described above. The F-test showed

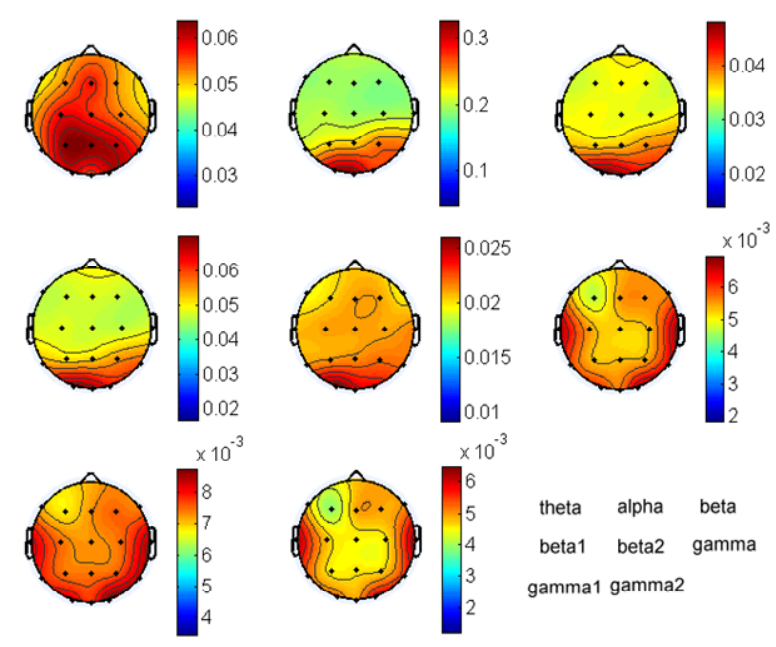

Figure 1. The topography of EEG power differences at 8 frequencies, from the comparison of the group $\mathrm{C} / \mathrm{T}$ minus the group $\mathrm{C} / \mathrm{C}$ for GRIN2B. Right lower corner is the alignment of subplots based on frequency.

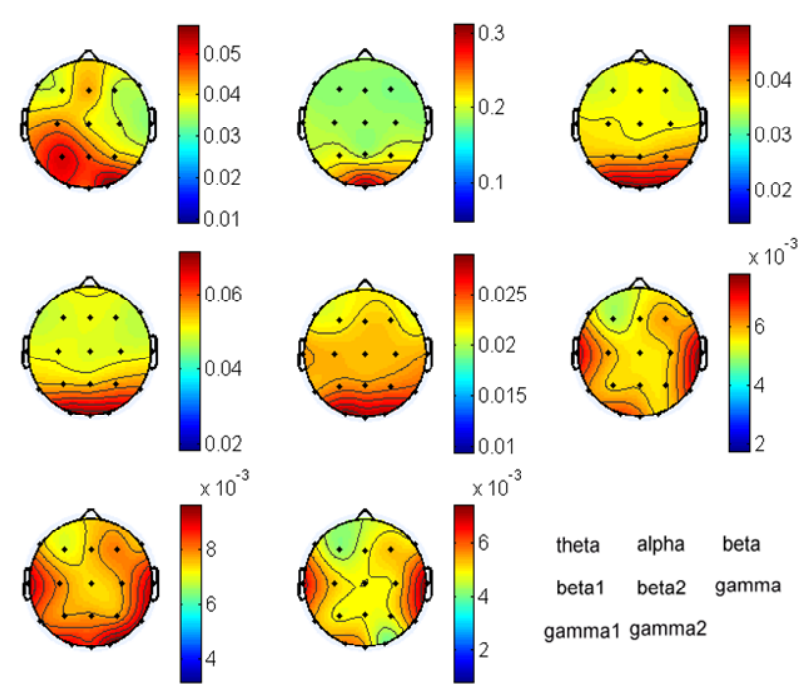

Figure 2. The topography of EEG power differences at 8 frequencies, from the comparison of the group $\mathrm{C} / \mathrm{T}$ minus the group T/T for GRIN2B. Right lower corner is the alignment of subplots based on frequency. significant between-group differences at occipital-gammal $(P=0.0102)$, see Table 1 for detail.

\section{DISCUSSION}

There are several subunits of the NMDA receptor, including NR1, NR2A-D and NR3A-B. The composite heteromers of NMDAR subunits carry varied physiological properties. NR2B of NMDA receptor, GRIN2B, has been of interest given its significant impact on neural development, excitotoxicity and plasticity. The polymorphism of GRIN2B has been associated with various neuro-psychiatric diseases and with the behavioral manifestation of pre-pulse inhibition [1,3,6-8,12,22,23]. The usual technique of gene knock-out is not applicable to exploring GRIN2B functioning because of consequent perinatal lethality. Akashi et al. tackled this issue by generating a conditional GRIN2B ablation in hippocampal CA3 pyramidal cells and discovered that the GRIN2B is not only important in NMDAR channel function but also in the formation/maintenance/regulation of the neuronal cyto-architecture [20]. We investigated the neural influence of GRIN2B via an approach of imaging genetics by combining GRIN2B C2664T polymorphism and resting EEG in the healthy young female population. The result of our regional power analysis was generally negative, with no significant between-group differences over 18 electrodes and 9 frequency bands with respect to the results of ANOVA and independent t-tests. At a looser statistical threshold with $P<0.01$, the heterozygous $\mathrm{C} / \mathrm{T}$ group had higher regional power at sparse electrodefrequency pairs, especially in posterior brain regions, when compared with the two homozygous groups $\mathrm{C} / \mathrm{C}$ and $\mathrm{T} / \mathrm{T}$. It is interesting that our non-parametric analysis demonstrated a trend of higher global power in the heterozygous group, regardless of spectrum, with very striking statistics. The global power was equivalent between the two homozygous groups.

Our prominent finding at the scale of a global trend was compatible with the wide distribution of NMDAR in the brain [21]. The observation that the heterozygous group had the higher global power was of particular interest given that it is also concordant with the well-known inverted-U-shaped response curve of the NMDAR system. The inverted-U response curve has been observed over board contexts of NMDAR modulation using various agonists and antagonists, including avoidance learning, spatial learning, memory performance, the breaking point for cocaine self-administration, messenger RNA expression, expression and phosphorylation of NMDA-signaling related proteins and the neuro-protection effect in global ischemia and so on $[26,27,38-43]$. This study complemented previous findings and showed a possible inverted-U-shaped impact of NMDAR on neural synchronization, manifested 
Table 1. The mean EEG power of frontal, temporal, centro-parietal and occipital regions across 8 frequency bands of the 3 genotypes of GRIN2B $(\mathrm{C} / \mathrm{C}, \mathrm{C} / \mathrm{T}$ and $\mathrm{T} / \mathrm{T})$.

\begin{tabular}{ccccccccccccccccc}
\hline & theta & alpha & beta & beta1 & beta2 & gamma & gamma1 & gamma2 \\
\hline $\mathrm{C} / \mathrm{C}$ & 0.164 & 0.340 & 0.039 & 0.049 & 0.030 & 0.008 & 0.013 & 0.006 & Frontal \\
& 0.253 & 0.601 & 0.062 & 0.080 & 0.045 & 0.008 & 0.014 & 0.005 & Centro-Parietal \\
& 0.258 & 1.182 & 0.095 & 0.125 & 0.064 & 0.011 & 0.019 & 0.008 & Occipital \\
$\mathrm{C} / \mathrm{T}$ & 0.195 & 0.350 & 0.049 & 0.059 & 0.039 & 0.011 & 0.017 & 0.009 & Frontal \\
& 0.175 & 0.512 & 0.068 & 0.085 & 0.050 & 0.016 & 0.023 & 0.014 & Temporal \\
& 0.309 & 0.685 & 0.078 & 0.099 & 0.058 & 0.011 & 0.019 & 0.007 & Centro-Parietal \\
& 0.311 & 1.505 & 0.142 & 0.195 & 0.089 & 0.016 & 0.027 & 0.012 & Occipital \\
$\mathrm{T} / \mathrm{T}$ & 0.182 & 0.345 & 0.039 & 0.047 & 0.031 & 0.009 & 0.014 & 0.007 & Frontal \\
& 0.153 & 0.461 & 0.047 & 0.058 & 0.035 & 0.010 & 0.014 & 0.008 & Temporal \\
& 0.280 & 0.645 & 0.060 & 0.076 & 0.044 & 0.008 & 0.014 & 0.005 & Centro-Parietal \\
& 0.261 & 1.235 & 0.088 & 0.117 & 0.058 & 0.012 & 0.018 & 0.010 & Occipital \\
\hline
\end{tabular}

The mean power $\mathrm{C} / \mathrm{T}$ group is greater than that of $\mathrm{C} / \mathrm{C}$ group and $\mathrm{T} / \mathrm{T}$ group at each frequency-region pair. The $\mathrm{F}$-test showed significant between-group differences at occipital-gammal ( $\mathrm{P}=0.0102<$ threshold 0.0127$)$.

as cortico-electrical power.

In this study, the impact of GRIN2B C2664T polymerphism neither showed region preference nor spectrum specificity on cortical EEG oscillation, implying a very fundamental neural property mediated by GRIN2B. GRIN2B is important in the post-synaptic macro-molecular organization, formation/maintenance of the dendritic spine, and cytoskeleton, predominant in the early postnatal brain and followed by the NR2B-NR2A switch where NR2A-containing NMDAR gradually outnumbered the NR2B-containing analog [20]. Neural modeling suggested that the generation of neural oscillation relies on the interaction between the sub-components of neural mass [44-46]. We thus speculated that the differential influence of GRIN2B C2664T genotypes on the global electrical activities may have to do with its crucial roles in channel functioning and in neural architecture regulation shaped during early development, and lasting through adulthood. It is also possible that our finding reflected the influence of GRIN2B on the deep subcortical structures, such as reticular formation, which resonate with the cortical network to generate the EEG oscillatory phenomenon.

Together with the early influence of GRIN2B on neural development and the inverted-U-shaped response in the NMDA system, our EEG finding further implicated a different strategy to probe the genetic association of GRIN2B. Unlike the traditional approach to access allele risk to certain disease or allele contribution to the biopsychological profile, it may be informative to compare heterozygote and homozygote groups. This stratification strategy could be particularly worthwhile to examine with respect to the NMDA and dopamine system [25-27].

The NMDA gene has been linked to a variety of neurological and psychiatric conditions. There are few reports exploring the influence of NMDA-NR2B polymerphism on the regional neural activity in the human brain. We demonstrated that the silent mutation C2664T of GRIN2B differentiated cortical electrical power at the scale of global trend, with the homozygous group, $\mathrm{C} / \mathrm{C}$ and $\mathrm{T} / \mathrm{T}$, associated with reduced EEG power regardless of frequency bands. Clarifying whether this finding possesses clinical implication, gender bias, or reflects only the GRIN2B influence in early developmental stage warrants further studies.

\section{ACKNOWLEDGMENTS}

This work was supported by grant DOH94-NNB-1035 from the Department of Health, Taiwan, ROC, and grant KS92-015 from the KaiSuan Psychiatric Hospital-Kaohsiung. We are grateful to Mr. Gosalia who helped us to prepare this manuscript.

\section{REFERENCES}

[1] Li, D. and He, L. (2007) Association study between the NMDA receptor 2B subunit gene (GRIN2B) and schizophrenia: A HuGE review and meta-analysis. Genetics in Medicine, 9, 4-8. doi:10.1097/01.gim.0000250507.96760.4b

[2] Liu, Y., Wong, T.P., Aarts, M., Rooyakkers, A., Liu, L., Lai, T.W., Wu, D.C., Lu, J., Tymianski, M., Craig, A.M. and Wang, Y.T. (2007) NMDA receptor subunits have differential roles in mediating excitotoxic neuronal death 
both in vitro and in vivo. Journal of Neuroscience, 27, 2846-2857. doi:10.1523/JNEUROSCI.0116-07.2007

[3] Jiang, H. and Jia, J. (2009) Association between NR2B subunit gene (GRIN2B) promoter polymorphisms and sporadic Alzheimer's disease in the North Chinese popuation. Neuroscience Letters, 450, 356-360. doi:10.1016/i.neulet.2008.10.075

[4] Li, L., Fan, M., Icton, C.D., Chen, N., Leavitt, B.R., Hayden, M.R., Murphy, T.H. and Raymond, L.A. (2003) Role of NR2B-type NMDA receptors in selective neurodegeneration in Huntington disease. Neurobiology of Aging, 24, 1113-1121. doi:10.1016/j.neurobiolaging.2003.04.003

[5] Tsai, S.J., Liu, H.C., Liu, T.Y., Cheng, C.Y. and Hong, C.J. (2002) Association analysis for the genetic variants of the NMDA receptor subunit 2b and Alzheimer's disease. Dementia and Geriatric Cognitive Disorders, 13, 91-94. doi:10.1159/000048639

[6] Arnold, P.D., Rosenberg, D.R., Mundo, E., Tharmalingam, S., Kennedy, J.L. and Richter, M.A. (2004) Association of a glutamate (NMDA) subunit receptor gene (GRIN2B) with obsessive-compulsive disorder: A preliminary study. Psychopharmacology, 174, 530-538. doi:10.1007/s00213-004-1847-1

[7] Biermann, T., Reulbach, U., Lenz, B., Frieling, H., Muschler, M., Hillemacher, T., Kornhuber, J. and Bleich, S. (2009) $\mathrm{N}$-methyl-D-aspartate $2 \mathrm{~b}$ receptor subtype (NR2B) promoter methylation in patients during alcohol withdrawal. Journal of Neural Transmission, 116, 615-622. doi:10.1007/s00702-009-0212-2

[8] Kim, J.H., Park, M., Yang, S.Y., Jeong, B.S., Yoo, H.J., Kim, J.W., Chung, J.H. and Kim, S.A. (2006) Association study of polymorphisms in N-methyl-D-aspartate receptor 2B subunits (GRIN2B) gene with Korean alcoholism. Neuroscience Research, 56, 220-223.

doi:10.1016/j.neures.2006.06.013

[9] Ridge, J.P., Ho, A.M. and Dodd, P.R. (2009) Sex differences in NMDA receptor expression in human alcoholics. Alcohol and Alcoholism, 44, 594-601. doi:10.1093/alcalc/agp052

[10] Ridge, J.P., Ho, A.M., Innes, D.J. and Dodd, P.R. (2008) The expression of NMDA receptor subunit mRNA in human chronic alcoholics. Annals of the New York Academy of Sciences, 1139, 10-19. doi:10.1196/annals.1432.053

[11] Tadic, A., Dahmen, N., Szegedi, A., Rujescu, D., Giegling, I., Koller, G., Anghelescu, I., Fehr, C., Klawe, C., Preuss, U.W., Sander, T., Toliat, M.R., Singer, P., Bondy, B. and Soyka, M. (2005) Polymorphisms in the NMDA subunit $2 \mathrm{~B}$ are not associated with alcohol dependence and alcohol withdrawal-induced seizures and delirium tremens. European Archives of Psychiatry and Clinical Neuroscience, 255, 129-135. doi:10.1007/s00406-004-0545-7

[12] Wernicke, C., Samochowiec, J., Schmidt, L.G., Winterer, G., Smolka, M., Kucharska-Mazur, J., Horodnicki, J., Gallinat, J. and Rommelspacher, H. (2003) Polymorphisms in the N-methyl-D-aspartate receptor 1 and $2 \mathrm{~B}$ subunits are associated with alcoholism-related traits. Biological Psychiatry, 54, 922-928. doi:10.1016/S0006-3223(03)00072-6

[13] Koronyo-Hamaoui, M., Frisch, A., Stein, D., Denziger, Y., Leor, S., Michaelovsky, E., Laufer, N., Carel, C., Fennig,
S., Mimouni, M., Ram, A., Zubery, E., Jeczmien, P., Apter, A., Weizman, A. and Gak, E. (2007) Dual contribution of NR2B subunit of NMDA receptor and SK3 $\mathrm{Ca}^{2+}$-activated $\mathrm{K}^{+}$channel to genetic predisposition to anorexia nervosa. Journal of Psychiatric Research, 1, 160-167. doi:10.1016/j.jpsychires.2005.07.010

[14] Moddel, G., Jacobson, B., Ying, Z., Janigro, D., Bingaman, W., Gonzalez-Martinez, J., Kellinghaus, C., Prayson, R.A. and Najm, I.M. (2005) The NMDA receptor NR2B subunit contributes to epileptogenesis in human cortical dysplasia. Brain Research, 1046, 10-23. doi:10.1016/j.brainres.2005.03.042

[15] Najm, I.M., Ying, Z., Babb, T., Mohamed, A., Hadam, J., LaPresto, E., Wyllie, E., Kotagal, P., Bingaman, W., Foldvary, N., Morris, H. and Luders, H.O. (2000) Epileptogenicity correlated with increased N-methyl-D-aspartate receptor subunit NR2A/B in human focal cortical dysplasia. Epilepsia, 41, 971-976. doi:10.1111/j.1528-1157.2000.tb00281.x

[16] Ying, Z., Babb, T.L., Comair, Y.G., Bingaman, W., Bushey, M. and Touhalisky, K. (1998) Induced expression of NMDAR2 proteins and differential expression of NMDAR1 splice variants in dysplastic neurons of human epileptic neocortex. Journal of Neuropathology and Experimental Neurology, 57, 47-62. doi:10.1097/00005072-199801000-00007

[17] Kutsuwada, T., Sakimura, K., Manabe, T., Takayama, C., Katakura, N., Kushiya, E., Natsume, R., Watanabe, M., Inoue, Y., Yagi, T., Aizawa, S., Arakawa, M., Takahashi, T., Nakamura, Y., Mori, H. and Mishina, M. (1996) Impairment of suckling response, trigeminal neuronal pattern formation, and hippocampal LTD in NMDA receptor epsilon 2 subunit mutant mice. Neuron, 16, 333-344. doi:10.1016/S0896-6273(00)80051-3

[18] Sakimura, K., Kutsuwada, T., Ito, I., Manabe, T., Takayama, C., Kushiya, E., Yagi, T., Aizawa, S., Inoue, Y., Sugiyama, H., et al. (1995) Reduced hippocampal LTP and spatial learning in mice lacking NMDA receptor epsilon 1 subunit. Nature, 373, 151-155. doi:10.1038/373151a0

[19] Zhou, M. and Baudry, M. (2006) Developmental changes in NMDA neurotoxicity reflect developmental changes in subunit composition of NMDA receptors. Journal of Neuroscience, 26, 2956-2963. doi:10.1523/JNEUROSCI.4299-05.2006

[20] Akashi, K., Kakizaki, T., Kamiya, H., Fukaya, M., Yamasaki, M., Abe, M., Natsume, R., Watanabe, M. and Sakimura, K. (2009) NMDA receptor GluN2B (GluR epsilon 2/NR2B) subunit is crucial for channel function, postsynaptic macromolecular organization, and actin cytoskeleton at hippocampal CA3 synapses. Journal of Neuroscience, 29, 10869-10882. doi:10.1523/JNEUROSCI.5531-08.2009

[21] Schito, A.M., Pizzuti, A., Di Maria, E., Schenone, A., Ratti, A., Defferrari, R., Bellone, E., Mancardi, G.L., Ajmar, F. and Mandich, P. (1997) mRNA distribution in adult human brain of GRIN2B, a N-methyl-D-aspartate (NMDA) receptor subunit. Neuroscience Letters, 239, 49-53. doi:10.1016/S0304-3940(97)00853-7

[22] Spooren, W., Mombereau, C., Maco, M., Gill, R., Kemp, J.A., Ozmen, L., Nakanishi, S. and Higgins, G.A. (2004) Pharmacological and genetic evidence indicates that combined inhibition of NR2A and NR2B subunit containing 
NMDA receptors is required to disrupt prepulse inhibittion. Psychopharmacology, 175, 99-105. doi:10.1007/s00213-004-1785-y

[23] Hokyo, A., Kanazawa, T., Uenishi, H., Tsutsumi, A., Kawashige, S., Kikuyama, H., Glatt, S.J., Koh, J., Nishimoto, Y., Matsumura, H., Motomura, N. and Yoneda, H. (2010) Habituation in prepulse inhibition is affected by a polymorphism on the NMDA receptor $2 \mathrm{~B}$ subunit gene (GRIN2B). Psychiatric Genetics, 20, 191-198. doi:10.1097/YPG.0b013e32833a201d

[24] Hong, C.J., Yu, Y.W., Lin, C.H., Cheng, C.Y. and Tsai, S.J. (2001) Association analysis for NMDA receptor subunit 2B (GRIN2B) genetic variants and psychopathology and clozapine response in schizophrenia. Psychiatric Genetics, 11, 219-222. doi:10.1097/00041444-200112000-00007

[25] Stewart, C.V. and Plenz, D. (2006) Inverted-U profile of dopamine-NMDA-mediated spontaneous avalanche recurrence in superficial layers of rat prefrontal cortex. Journal of Neuroscience, 26, 8148-8159. doi:10.1523/JNEUROSCI.0723-06.2006

[26] Ranaldi, R., French, E. and Roberts, D.C. (1996) Systemic pretreatment with MK-801 (dizocilpine) increases breaking points for self-administration of cocaine on a progressive-ratio schedule in rats. Psychopharmacology, 128, 83-88. doi:10.1007/s002130050113

[27] Bar-Joseph, A., Berkovitch, Y., Adamchik, J. and Biegon, A. (1994) Neuroprotective activity of HU-211, a novel NMDA antagonist, in global ischemia in gerbils. Molecular and Chemical Neuropathology, 23, 125-135. doi:10.1007/BF02815406

[28] Mulert, C., Juckel, G., Brunnmeier, M., Karch, S., Leicht, G., Mergl, R., Moller, H.J., Hegerl, U. and Pogarell, O. (2007) Prediction of treatment response in major depresssion: integration of concepts. Journal of Affective Disorders, 98, 215-225. doi:10.1016/j.jad.2006.07.021

[29] Jelic, V. and Kowalski, J. (2009) Evidence-based evaluation of diagnostic accuracy of resting EEG in dementia and mild cognitive impairment. Clinical EEG and Neuroscience, 40, 129-142.

[30] Neuper, C., Grabner, R.H., Fink, A., and Neubauer, A.C. (2005) Long-term stability and consistency of EEG eventrelated (de-)synchronization across different cognitive tasks. Clinical Neurophysiology, 116, 1681-1694. doi:10.1016/i.clinph.2005.03.013

[31] Hermens, D.F., Soei, E.X., Clarke, S.D., Kohn, M.R., Gordon, E. and Williams, L.M. (2005) Resting EEG theta activity predicts cognitive performance in attentiondeficit hyperactivity disorder. Pediatric Neurology, 32, 248-256. doi:10.1016/j.pediatrneurol.2004.11.009

[32] Hoptman, M.J. and Davidson, R.J. (1998) Baseline EEG asymmetries and performance on neuropsychological tasks. Neuropsychologia, 36, 1343-1353. doi:10.1016/S0028-3932(98)00023-2

[33] Coben, L.A., Chi, D., Snyder, A.Z. and Storandt, M. (1990) Replication of a study of frequency analysis of the resting awake EEG in mild probable Alzheimer's disease. Electroencephalography and Clinical Neurophysiology, 75, 148-154. doi:10.1016/0013-4694(90)90168-J

[34] Arning, L., Saft, C., Wieczorek, S., Andrich, J., Kraus, P.H. and Epplen, J.T. (2007) NR2A and NR2B receptor gene variations modify age at onset in Huntington disease in a sex-specific manner. Human Genetics, 122,
175-182. doi:10.1007/s00439-007-0393-4

[35] Ness, V., Arning, L., Niesert, H.E., Stuettgen, M.C., Epplen, J.T. and Beste, C. (2011) Variations in the GRIN2B gene are associated with risky decision-making. Neuropharmacology, 61, 950-956. doi:10.1016/i.neuropharm.2011.06.023

[36] Duffy, F.H., Lyer, G. and Surwillo, W.W. (1989) Clinical electroencephalography and topographical brain mapping. Springer-Verlag, New York. doi:10.1007/978-1-4613-8826-5

[37] Tsai, S.J., Liu, H.C., Liu, T.Y., Cheng, C.Y. and Hong, C.J. (2002) Association analysis for genetic variants of the NMDA receptor $2 b$ subunit (GRIN2B) and Parkinson's disease. Journal of Neural Transmission, 109, 483-488. doi: $10.1007 / \mathrm{s} 007020200039$

[38] Barber, T.A., Meyers, R.A. and McGettigan, B.F. (2010) Memantine improves memory for taste-avoidance learning in day-old chicks exposed to isolation stress. Pharmacology, Biochemistry and Behavior, 95, 203-208. doi:10.1016/j.pbb.2010.01.006

[39] Uslaner, J.M., Parmentier-Batteur, S., Flick, R.B., Surles, N.O., Lam, J.S., McNaughton, C.H., Jacobson, M.A. and Hutson, P.H. (2009) Dose-dependent effect of CDPPB, the mGluR5 positive allosteric modulator, on recognition memory is associated with GluR1 and CREB phosphorylation in the prefrontal cortex and hippocampus. Neuropharmacology, 57, 531-538. doi:10.1016/j.neuropharm.2009.07.022

[40] Xi, D., Zhang, W., Wang, H.X., Stradtman, G.G. and Gao, W.J. (2009) Dizocilpine (MK-801) induces distinct changes of N-methyl-D-aspartic acid receptor subunits in parvalbumin-containing interneurons in young adult rat prefrontal cortex. International Journal of Neuropsychopharmacology, 12, 1395-1408. doi:10.1017/S146114570900042X

[41] Wise, L.E. and Lichtman, A.H. (2007) The uncompetitive N-methyl-D-aspartate (NMDA) receptor antagonist memantine prolongs spatial memory in a rat delayed radial-arm maze memory task. European Journal of Pharmacology, 575, 98-102. doi:10.1016/j.ejphar.2007.07.059

[42] Matsuoka, N. and Aigner, T.G. (1996) D-cycloserine, a partial agonist at the glycine site coupled to N-methylD-aspartate receptors, improves visual recognition memory in rhesus monkeys. Journal of Pharmacology and Experimental Therapeutics, 278, 891-897.

[43] Mathis, C., de Barry, J., and Ungerer, A. (1991) Memory deficits induced by gamma-L-glutamyl-L-aspartate and D-2-amino-6-phosphonovalerate in a Y-maze avoidance task: relationship to NMDA receptor antagonism. Psychopharmacology, 105, 546-552. doi:10.1007/BF02244378

[44] Lopes da Silva, F.H., Pijn, J.P., Velis, D. and Nijssen, P.C. (1997) Alpha rhythms: Noise, dynamics and models. International Journal of Psychophysiology, 26, 237-249. doi:10.1016/S0167-8760(97)00767-8

[45] David, O. and Friston, K.J. (2003) A neural mass model for MEG/EEG: Coupling and neuronal dynamics. Neuroimage, 20, 1743-1755. doi:10.1016/j.neuroimage.2003.07.015

[46] Felleman, D.J. and Van Essen, D.C. (1991) Distributed hierarchical processing in the primate cerebral cortex. Cerebral Cortex, 1, 1-47. doi:10.1093/cercor/1.1.1-a 